\title{
The Glycosaminoglycans of Normal and Arthritic Cartilage
}

\author{
Henry J. Mankin and Louis Lippiello \\ From the Hospital for Joint Diseases, Mount Sinai School of Medicine of the \\ City University of New York, New York 10035
}

A в S T R A C T The cartilages from the hip joints of 13 normal and 15 osteoarthritic humans were analyzed for glycosaminoglycan content and distribution. The GAGs were separated by elution with $\mathrm{CPC}$ on a short cellulose column by the technique of Svejcar and Robertson after digestion of the tissue with pronase and papain. The eluates were identified by a variety of methods including determination of molar ratios, $\mathrm{N}$-acetyl-hexosamine determinations after hyaluronidase treatment and thin-layer chromatography of unhydrolyzed and hydrolyzed GAGs.

From the data obtained, it was demonstrated that cartilage from arthritic patients showed a significant increase in the concentration of chondroitin 4-sulfate and a significant decrease in keratan sulfate, with only slight changes in the total amount of GAG present. Calculations of the molar ratios showed variation in the sulfation with chondroitin 4-sulfate appearing in the "supersulfated" state in the arthritic cartilage.

The data lead to speculation regarding the process of osteoarthritis, and it is concluded that the changes seen are more likely to represent an altered pattern of synthesis rather than selective degradation. Since the changes suggest a younger cartilage, a theory is advanced that the chondrocyte responds to the chronic stress of osteoarthritis by modulation to a chondroblastic phase.

\section{INTRODUCTION}

The acidic glycosaminoglycans (GAGs $(1))^{1}$ of articular cartilage have been identified as chondroitin 6-sulfate, chondroitin 4-sulfate, and keratan sulfate (2-4). Because of the difficulty of separating, purifying, and

Dr. Mankin's present address is the Hospital for Joint Diseases, N. Y. 10035.

Mr. Lippiello's present address is the Department of Chemistry, Cornell University, Ithaca, N. Y.

Received for publication 3 August 1970 and in revised form 4 March 1971.

${ }^{1}$ Albreviations used in this paper: GAG, glycosaminoglycans. identifying small quantities of the GAGs, only a few studies have been performed using articular cartilage. These have suggested that the relative percentages of chondroitin 4-sulfate, chondroitin 6-sulfate, and keratan sulfate, vary in immature and adult tissues but remain fairly constant with advancing age (2-11).

Histochemical and biochemical studies of cartilage from osteoarthritic human joints have shown a significant decrease in the GAG content (12-17), and that the decrease in approximately proportional to the severity of the disease. Since it has also been shown that osteoarthritic cartilage has an increased rate of protein and polysaccharide syntheses $(12,17,18)$, it has been postulated that the observed activity is a "feedback" response related to an increased selective enzymatic degradation of the protein polysaccharides of the matrix $(14,15,17,19)$.

The study reported here describes the results of "a comparison of the absolute and relative amounts of the component GAGs in articular cartilage from 15 patients with osteoarthritis of the hip and 13 patients with normal hips who had suffered a fracture of the femoral neck. The date demonstrates statistically significant alterations in the absolute and relative amounts of the GAGs in the osteoarthritic cartilage. The possible significance and interpretation of these findings are discussed.

\section{METHODS}

Human cartilage used for this study was obtained at the time of surgery from two groups of patients: "the normals", 13 patients who had suffered a fresh fracture of the neck of the femur (average age, 77.5; median age, 79) : and "osteoarthritics", 15 patients who had varying degrees of osteoarthritis as diagnosed by X-ray and histological studies (average age, 56.3 ; median age, 52). (Fig. 1) Both groups were treated by prosthetic replacement, the former group with Austin-Moore endoprostheses and the latter with low-friction total replacement prostheses (Charnley), so that cartilage from the entire femoral head was available for study. Patients known to have rheumatoid arthritis or osteonecrosis were excluded from the study.

At the time of removal of the femoral head, small segments of the cartilage and underlying bone were resected 
and studied by radiologic, histologic, and histochemical techniques, to establish that the cartilage was either normal or osteoarthritic, and the remainder of the cartilage was subjected to analysis for GAGs.

Hexosamines were determined by the method of Rondle and Morgan (20) and uronic acid by both the carbazole (Bitter and Muir [21]) and orcinol (Khym and Doherty [22]) techniques using glucuronolactone as a standard. Sulfate was measured by the benzidine technique (Antonopoulos [23]) and hexose (as galactose) by the anthrone reaction (24). N-acetyl hexosamine was measured by the method of Reissig, Strominger, and Leloir (25) and protein by the method of Lowry, Rosebrough, Farr, and Randall (26).

Chromatographic identification of hexoses and hexosamines was performed by thin-layer technique using ITLCSA silicate impregnated glass fiber sheets (Gelman Instrument Company, Ann Arbor, Mich.) and an n-propanol: ethanol: $\mathrm{H}_{2} \mathrm{O}(7: 2: 1)$ system after hydrolysis with $4 \mathrm{~N}$ hydrochloric acid for $6 \mathrm{hr}$ and neutralization of the hydrolysate. Mobility was compared against a variety of sugar standards including glucose, glucosamine, galactose, galactosamine, fucose, mannose, and sialic acid. Spots were visualized with a silver nitrate spray or $50 \%$ sulfuric acid char.

The unhydrolyzed GAG preparations were identified chromatographically after CPC fractionation, pooling, and conversion to $\mathrm{Na}$ salts by thin-layer chromatography using a sequential development $(2 \mathrm{~cm} /$ solvent $)$ on ITLC-S silicate impregnated glass fiber (Gelman Instrument Company) with ethanol, calcium acetate, and acetic acid of varying concentrations (27). Localization was achieved by staining with $1 \%$ toluidine blue and/or $50 \%$ sulfuric acid charring technique, or for the uronic acid-containing-GAGs, the carbazole reaction. Mobility of the materials studied were compared against hyaluronic acid, chondroitin 4- and 6-sulfate, keratan sulfate, dermatan sulfate, and heparan sulfate (generously provided by Dr. M. B. Mathews, Department of Pediatrics, University of Chicago, Chicago, Ill.) and chondroitin 4-sulfate of a different tissue source (a gift of Dr. P. Hoffman, Research Institute for Skeletomuscular Diseases of the Hospital for Joint Diseases and Medical Center, N. Y.)

The GAGs were isolated from the fresh resected cartilage in the following manner. Tissue segments were dehydrated in absolute ethanol, lyophilized in a freezing and drying

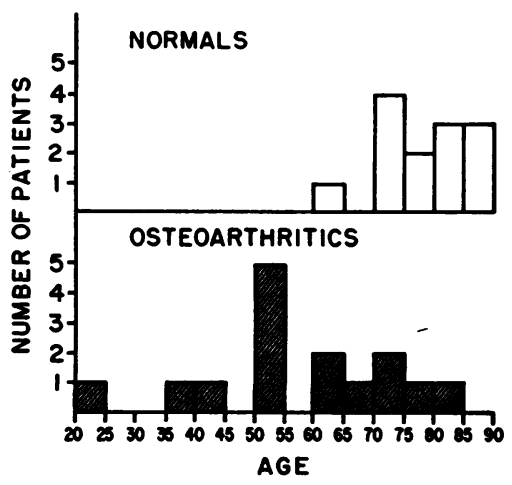

FIgURE 1 Age distribution of patients in the normal and osteoarthritic groups. As can be seen, the normal group was considerably older (21 $\mathrm{yr}$, average) than the osteoarthritic, but considerable overlap exists.
TABLE I

Recovery of Sugars after Digestion of Cartilage Samples ( $\mu g / m g d r y w t)$

\begin{tabular}{|c|c|c|c|c|c|c|}
\hline & \multicolumn{3}{|c|}{ Normal } & \multicolumn{3}{|c|}{ Arthritic } \\
\hline & $\begin{array}{c}\text { Pre } \\
\text { digest.* }\end{array}$ & $\begin{array}{c}\text { Post } \\
\text { digest. } \neq\end{array}$ & Rec. & $\begin{array}{c}\text { Pre } \\
\text { digest.* }\end{array}$ & $\begin{array}{c}\text { Post } \\
\text { digest. } \neq\end{array}$ & Rec. \\
\hline Uronic acid & 36.6 & 27.2 & $\begin{array}{c}\% \\
74.3\end{array}$ & 19.4 & 19.2 & $\begin{array}{c}\% \\
98.9\end{array}$ \\
\hline Hexosamine & 37.4 & 35.8 & 95.7 & 32.0 & 24.7 & 77.2 \\
\hline Hexose & 20.4 & 14.5 & 71.1 & 7.0 & 4.4 & 62.9 \\
\hline TOTAL & 94.4 & 77.5 & & 58.4 & 48.3 & \\
\hline $\begin{array}{l}\text { Recovery for } \\
\text { total }\end{array}$ & \multicolumn{3}{|c|}{$82.1 \%$} & & \multicolumn{2}{|c|}{$82.7 \%$} \\
\hline
\end{tabular}

* Values are averages of results of analysis of four samples in each group. † Values were determined by analysis of pooled samples (see text).

Comparison of values for the component sugars of the GAGs obtained by analysis pre and postenzyme digestion. Recovery was over $82 \%$ for both normal and arthritic cartilage and, although there was some variation of enzyme effect in the individual sugars, the values for the two series are comparable.

apparatus (Virtis Company, Gardiner, N. Y.), weighed, minced, and heated in phosphate buffer in a boiling water bath for $20 \mathrm{~min}$ to destroy hydrolytic enzymes. After cooling, $0.4 \%$ pronase solution in acetate buffer was added to give a final concentration of $20 \mu \mathrm{g}$ enzyme $/ \mathrm{mg}$ dry tissue weight and the material incubated at $62^{\circ} \mathrm{C}$ for $12 \mathrm{hr}$ and then the digestion repeated. A second digestion was performed using crude papain $(0.2 \%$ solution in phosphate buffer [ $\mathrm{pH} 7.0,0.1 \mathrm{M}]$ containing $0.01 \mathrm{M}$ cysteine and 0.01 $M$ EDTA) at a concentration of $5 \mu \mathrm{g}$ enzyme/mg dry tissue weight for $18 \mathrm{hr}$ at $65^{\circ} \mathrm{C}$.

The mixture was cooled, treated with $5 \%$ trichloroacetic acid, and centrifuged. The supernate containing the GAG was treated with three times the volume of $5 \%$ potassium acetate in absolute ethanol at $4^{\circ} \mathrm{C}$., and the precipitate so obtained was washed with absolute ethanol, ethanol:ether $(1: 1)$ and ether, freeze-dried, resuspended in water, dialyzed against running distilled water, and then relyophilized. The final purified dried GAG was weighed and reconstituted in $0.075 \mathrm{M} \mathrm{NaCl}$ at a concentration of $1 \mathrm{mg} / \mathrm{ml}$ in preparation for the cetyl pyridinium chloride-cellulose column fractionation. Analysis for uronic acid, anthrone material, hexosamine, and noncollagen protein was completed before fractionation. An average protein value of $11 \%$ (normal) and $7.1 \%$ (arthritic) was found, and all subsequent determinations were corrected for this contamination in order to express the analytical data on a per mg dry weight of GAG basis. Recovery of GAG throughout the digestion phase was estimated by comparison with analytical values obtained for uronic acid, hexosamine, and hexose determinations on dry undigested material from four samples from each series. The percentage recovery for both normal and arthritic tissue was over $82 \%$, and although not uniform for all the sugars, was approximately the same in both series (Table I).

The purified GAG was then fractionated by a slight modification of a technique described by Svejcar and Robertson (28) employing a $3 \times 60 \mathrm{~mm}$ column packed with Whatman CF-11 cellulose. $\frac{1}{10} \mathrm{ml}$ of the $0.075 \mathrm{M} \mathrm{NaCl}$ solution of GAG (containing approximately $100 \mu \mathrm{g} \mathrm{GAG)} \mathrm{was} \mathrm{ap-}$ plied to the column and eluted successively with $1.0 \mathrm{ml}$ of 
TABLE II

Biochemical Data on the Pooled Fractions Obtained after CPC-Cellulose Column Separation of Normal and Arthritic Cartilage GAGs

\begin{tabular}{|c|c|c|c|c|c|c|c|c|c|}
\hline & \multirow[b]{2}{*}{ Fraction } & \multicolumn{2}{|c|}{ Uronic acid } & \multirow[b]{2}{*}{ Sulfate } & \multirow[b]{2}{*}{ Hexosamine } & \multirow[b]{2}{*}{ Hexose } & \multirow{2}{*}{$\begin{array}{c}\text { TLC } \\
\text { identification } \\
\text { of sugar }\end{array}$} & \multirow{2}{*}{$\begin{array}{c}\mathrm{N}-\mathrm{Ac} \\
\text { hexosamine } \\
\text { after } \\
\text { hyalu- } \\
\text { ronidase }\end{array}$} & \multirow{2}{*}{$\begin{array}{c}\text { TLC } \\
\text { identification } \\
\text { of samples }\end{array}$} \\
\hline & & Carbazole & Orcinol & & & & & & \\
\hline \multirow{5}{*}{ Normal } & & $m M$ & $m M$ & $m M$ & $m M$ & $m M$ & & & \\
\hline & 1 & 0.25 & 0.24 & 0.89 & 0.74 & 0.41 & $\begin{array}{l}\text { galactose } \\
\text { glucosamine } \\
\text { galactosamine }\end{array}$ & & $\begin{array}{l}\mathrm{KS}+ \\
\mathrm{Ch}-6-\mathrm{SO}_{4}\end{array}$ \\
\hline & 3 & 0.09 & 0.13 & 0.04 & 0.10 & - & galactosamine & + & $\mathrm{Ch}-6-\mathrm{SO}_{4}$ \\
\hline & 4 & 0.27 & 0.22 & 0.31 & 0.21 & - & galactosamine & - & $\mathrm{Ch}-4-\mathrm{SO}_{4}$ \\
\hline & 5 & 0.23 & 0.18 & 0.24 & 0.16 & - & galactosamine & + & $\mathrm{Ch}-6-\mathrm{SO}_{4}$ \\
\hline \multicolumn{10}{|l|}{ Arthritic } \\
\hline & 1 & 1.24 & 1.00 & 1.31 & 1.60 & 0.39 & $\begin{array}{l}\text { galactose } \\
\text { glucosamine } \\
\text { galactosamine }\end{array}$ & & $\begin{array}{l}\mathrm{KS}+ \\
\mathrm{Ch}-6-\mathrm{SO}_{4}\end{array}$ \\
\hline & 3 & 0.24 & 0.26 & 0.19 & 0.10 & - & galactosamine & + & $\mathrm{Ch}-6-\mathrm{SO}_{4}$ \\
\hline & 4 & 0.14 & 0.14 & 0.21 & 0.09 & - & galactosamine & - & $\mathrm{Ch}-4-\mathrm{SO}_{4}$ \\
\hline & 5 & 0.57 & 0.62 & 0.45 & 0.34 & - & galactosamine & + & $\mathrm{Ch}-6-\mathrm{SO}_{4}$ \\
\hline
\end{tabular}

See text for techniques and chemical methods.

$1 \% \mathrm{CPC}$ (fraction 1); $0.3 \mathrm{M} \mathrm{NaCl}$ (fraction 2); $0.3 \mathrm{M}$ $\mathrm{MgCl}_{2}$ (fraction 3); $40 \%$ n-propanol $/ 20 \%$ methanol and $1.5 \%$ acetic acid (fraction 4); $0.75 \mathrm{M} \mathrm{MgCl} 2+0.6$ acetic acid (fraction 5); $0.75 \mathrm{M} \mathrm{MgCl}_{2}$ (fraction 6); and $1.25 \mathrm{M}$ $\mathrm{MgCl}_{2}$ (fraction 7). The solvent for all solutions except fraction 7 was $0.05 \%$ CPC.

The seven fractions so obtained were separately assayed for their content of uronic acid and hexose and the results plotted as per cent distribution of recovered material and $\mu \mathrm{g} / \mathrm{mg}$ total GAG. Recovery was estimated by comparison with the total quantity applied to the column and averaged $97 \%$ for uronic acid and $103 \%$ for hexose. The values obtained for content of hexose and uronic acid were used to calculate the individual content and percentage of the different GAGs in each of the 28 femoral heads studied.

To identify the materials present in each of the fractions, 40 columns of pooled normal and pooled arthritic tissue were run, and the 7 fractions for each group were separately pooled. The $\mathrm{CPC}$ or $\mathrm{Mg}$ salt of the GAG obtained was converted back to the $\mathrm{Na}$ salt by the method described by Hjertquist and Vejlens (29).

The absence of iduronic acid was determined by comparison of the uronic acid values obtained by the carbazole and orcinol methods (2). Keratan sulfate was identified by thin-layer chromatographic identification of galactose and glucosamine after hydrolysis and by comparison against keratan sulfate in the second thin-layer system (see above). The chondroitin sulfates were identified by uronic acid: sulfate: hexosamine molar ratios, carbazole/orcinol characteristics, and by identification of galactosamine on thinlayer chromatography after hydrolysis. The 4 and 6 sulfated polysaccharide isomers were distinguished by analysis for $\mathrm{N}$-acetyl hexosamine after hyaluronidase treatment $(30)$ and by differences in mobility of the thin-layer system as compared with standards. Dermatan sulfate, heparan sulfate, and hyaluronic acid were not detected.

\section{RESULTS}

Identification of the glycosaminoglycans. Only fractions 1, 3, 4, and 5 contained significant amounts of the GAGs, and these were subjected to the studies described above for the purpose of identification. The results are shown in Tables II and III. It is apparent from these data that fraction 1 contains all of the keratan sulfate. In addition, substantial amounts of another GAG were present which contained uronic acid, hexosamine and sulfate, and had a mobility on chromatogram consistent with chondroitin 6-sulfate (Fig. 3).

Fractions 3, 4, and 5 in both the normal and arthritic cartilage showed a chemical composition consistent with chondroitin sulfate. The material from fraction 5 gives a positive reaction for $\mathrm{N}$-acetyl hexosamine after treatment with hyaluronidase (30) and had a mobility on thin-layer chromatography similar to chondroitin 6sulfate (Fig. 3). The material in fraction 4 showed a mobility identical to chondroitin 4-sulfate (Fig. 3) and gave a negative reaction after hyaluronidase treatment.

A small amount of uronic acid containing material was eluted in the third fraction $(<17 \%$ of the total GAGs). Although this gave a positive test for $\mathrm{N}$-acetyl hexosamine after hyaluronidase treatment, the mobility on TLC was slightly faster than that of the chondroitin 
6-sulfate standard (Fig. 3). Examination of the molar ratio data suggests that, at least in normal tissue, this fraction is low in sulfate, and it is certainly possible that this represents "chondroitin" either naturally occurring, or resulting from the separatory procedures.

Molar ratios. The molar ratios for the GAGs of the various fractions are shown in Table III. Because two different GAGs were eluted in fraction 1, the molar ratio for the keratan sulfate and chondroitin sulfate could only be estimated. This was accomplished by utilizing an empiric $1: 1.5: 1$ (hexose:sulfate: hexosamine) for the keratan sulfate $(31,32)$. The remainder of the molar ratios were calculated directly from the chemical determinations, and as can be seen, there is a decrease in sulfate concentration in fraction 3 of the normal tissue and a fairly marked "oversulfation" in fraction 4 of the arthritic cartilage.

Concentration and distribution of the GAGs. The GAG content was estimated by multiplying the amount of uronic acid or hexose for each fraction from each of the 28 samples by a specific factor as calculated from the derived molar ratio. For reasons indicated above, the chondroitin 6 -sulfate value was obtained by adding the amounts of GAG found in fractions 1,3 , and 5 .

The total content values are shown and compared in Table IV. It may be noted that there is a $22.4 \%$ decrease in the keratosulfate concentrations in the arthritic cartilage, significant at the $10 \%$ confidence level. No change is noted in the chondroitin 6-sulfate concentration, but a $35 \%$ increase is noted in the chondroitin 4

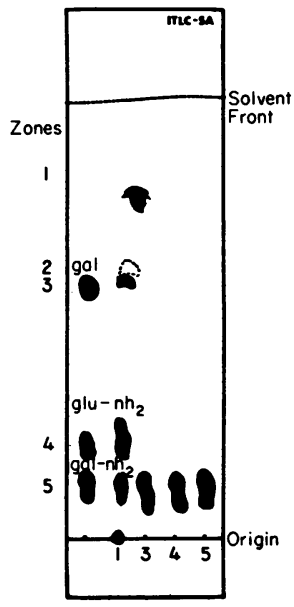

FIGURE 2 Drawing of a typical thin-layer chromatogram of the hexoses and amino hexoses after digestion of the GAG by $0.4 \mathrm{~N} \mathrm{HCl}$ for $16 \mathrm{hr}$ at $110^{\circ} \mathrm{C}$. Solvent system consisted of N-propanol: ethyl alcohol: $\mathrm{H}_{2} \mathrm{O} \quad(7: 2: 1)$, and spots were detected with $\mathrm{AgNO}_{3}$ spray. As can be seen, glucosamine and galactose were present only in fraction 1 , and fractions $1,3,4$, and 5 contained galactosamine (see Table I and text).
TABLE III

Molar Ratios

\begin{tabular}{|c|c|c|c|c|}
\hline \multicolumn{3}{|c|}{ Uronic acid: hexosamine: $\mathrm{SO}_{4}$} & \multicolumn{2}{|c|}{ Hexose: $\mathrm{SO}_{4}$ : hexosamine* } \\
\hline $\begin{array}{c}\text { Frac- } \\
\text { tion }\end{array}$ & Normal & Arthritic & Normal & Arthritic \\
\hline $\begin{array}{l}1 \\
3 \\
4 \\
5\end{array}$ & $\begin{array}{l}1.0: 1.3: 1.1 \\
1.0: 1.1: 0.4 \\
1.0: 0.8: 1.1 \\
1.0: 0.7: 1.0\end{array}$ & $\begin{array}{l}1.0: 1.0: 0.6 \\
1.0: 0.4: 0.8 \\
1.0: 0.6: 1.5 \\
1.0: 0.6: 0.8\end{array}$ & $1.0: 1.5: 1.0$ & $1.0: 1.5: 1.0$ \\
\hline
\end{tabular}

* Estimated on the basis of hexose content with sulfate to hexose ratio assigned a value of $1.5: 1$.

Molar ratios of the materials obtained in each fraction after CPC-cellulose column separation of normal and arthritic certilage GAGs. As indicated in the text, fraction 1 contained two GAGs, one of which was keratan sulfate. The molar ratio of the keratan sulfate was estimated from the hexose content by assigning arbitrarily a sulfate to hexose ratio of $1.5: 1$ and a hexosamine to hexose ratio of $1: 1$. This allowed calculation of the molar ratio for the other GAG present.

sulfate concentration $(P<0.2)$. The total GAG concentration is slightly decreased, but the values lack statistical validity $(P<0.30)$. Percentage distributions of the GAGs are shown in Table V. In the arthritic cartilage, keratosulfate is reduced by $11.4 \%$ and chondroitin $4-$ and 6 -sulfates increased by $36.8 \%$ and $8.7 \%$ respectively. These values are all statistically significant. The keratosulfate-chondroitin sulfate ratio is considerably reduced in the arthritic tissues $(20 \%)(P<0.1)$, and the chondroitin 4- and 6-sulfate ratio shows a $20.3 \%$ increase of doubtful significance $(P<0.20)$ (Table V).

Correlations. As indicated by the standard deviations and the tests of statistical validity, individual sample variations were fairly widely distributed from the mean. An attempt was made to correlate the percentage distribution of the GAGs with the total hexosamine content of the sample (a theoretical indicator of the severity of the process) and the age or sex of the patient. No significant correlation was noted.

\section{DISCUSSION}

It is apparent from examination of the two series of patients that the "normal controls" are neither "normal" nor "controls" as compared with the osteoarthritic group. These were elderly patients who had suffered an intracapsular fracture of the neck of the femur from 24 to $48 \mathrm{hr}$ before resection of the femoral head, and one must presume some trauma to the cartilage surface, capsular rupture, bleeding, or partial devascularization of the underlying bone. Although it is unlikely that this state would greatly alter the pattern of GAGs, the possibility of acceleration of an autodegradative process exists, and if the patients were not treated rapidly, such 


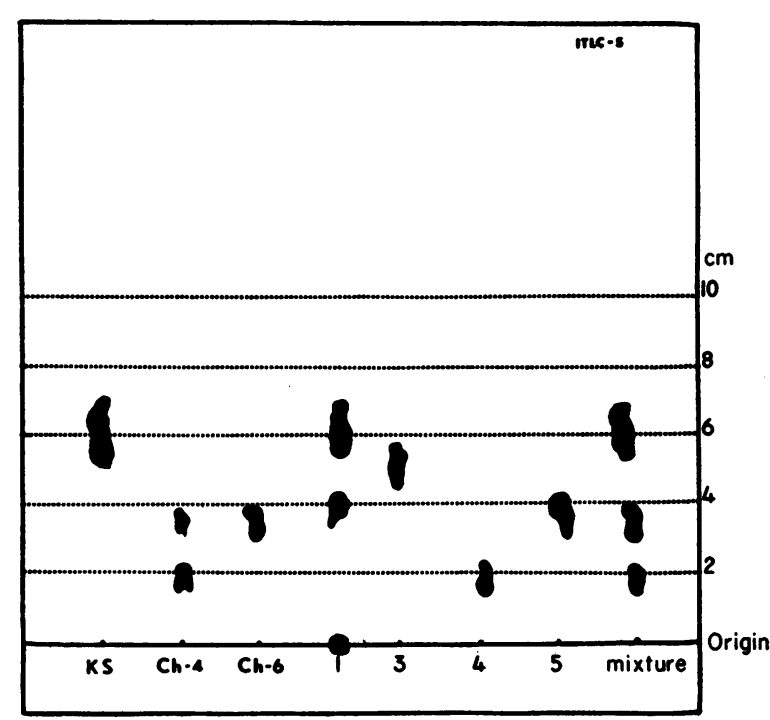

FIGURE 3 Drawing of a typical thin-layer chromatogram of the unhydrolyzed GAG samples. The method uses a sequential development on ITLC-S silicate impregnated glass fiber with ethanol, calcium acetate, and acetic acid of varying concentrations. Localization was achieved by staining with $1 \%$ toluidine blue or a $50 \%$ sulfuric acid charring technique. Note that keratosulfate has a distinctive spot at $6 \mathrm{~cm}$, chondroitin 4- is polydisperse with a major spot at $2 \mathrm{~cm}$ and a secondary one at $4 \mathrm{~cm}$, and chondroitin 6 - shows a distinctive spot at $4 \mathrm{~cm}$. The materials eluted from the columns are shown in the spaces marked $1,3,4$, and 5 , and a mixture of the three is also shown. From these data, it is evident that GAG materials with mobility essentially equivalent to chondroitin 6-sulfate were present in fractions 1,3 , and 5. Fraction 3 contains material with the same mobility as chondroitin 4-sulfate and fraction 1, a material similar to keratan sulfate. The behavior of the mixture indicates the resolution of the system. (Chromatograms of the normal and arthritic cartilage did not differ in distribution of materials in fractions or localization of the spots.)

factors could be significant. In all fracture patients, the time lapse between injury and surgery did not exceed 48 hr.

Of considerably greater significance is the difference in age between the two patient groups. The average age of the control group was $21 \mathrm{yr}$ older than the arthritic although, as can be noted in Fig. 1, considerable overlap was present. In 1959, Kaplan and Meyer (5) noted a linear increase in keratan sulfate content of rib cartilage with age associated with a simultaneous decline in the concentrations of the chondroitin sulfates. Previously, Loewi (11) reported considerable change in the hexosamine and sulfate concentrations of both costal cartilage and articular cartilage, but only slight change was noted between ages 40 and 89 in his series. In 1958, Stedworthy, Masters, and Shetlar (10) corroborated the stability of the glucosamine content of costal cartilage after age 25 , and the recent studies of Mathews and Glagov (8) showed that the chondroitin 4- and 6-sulfate and keratosulfate concentrations of aging human rib cartilage remained essentially the same after the 5th decade. This lack of change with age was confirmed in articular cartilage by Bollet and Nance (13), Anderson and coworkers $(33,34)$ and Kuhn and Leppelmann (9), all of whom established the relative stability of the total and some of the component GAGs between the ages of 40 and 90 . To establish that the keratan sulfate values were not materially affected by age, 8 more femoral heads were obtained from patients without osteoarthritic disease whose ages ranged from 61 to 82 and the keratosulfate values for the entire group of 21 patients plotted against their ages. As can be seen in Fig. 4, there was no significant correlation and most of the values fell within the range of the standard deviation for the "normal" group.

Osteoarthritis is a focal disease, and histological studies have demonstrated marked variation in the process depending on the site studied. Even more important is the special problem related to the surgery. Patients are rarely subjected to replacement surgery for osteoarthritis unless the process is classified as a Collins III or IV (18). Since these classifications are characterized by areas of complete denudation of the surface to the underlying bone, samples in such patients, of necessity, must come from sites of less severe involvment or over the osteophytes. This may help explain some of the variation in these results as compared with those of Bollet $(12,13)$, whose patients had perhaps less severe arthritis but whose cartilage may have had more disease.

If one accepts the problems discussed above as being minimal or of minor significance, the data obtained seem to indicate the following: (a) In normal (aged) human hip articular cartilage, the GAGs account for about $15 \%$ of the dry weight, and the distribution of chondroitin 6-sulfate, chondroitin 4-sulfate and keratan sulfate is approximately 1 to 0.13 to 1.21 . (b) In cartilage from the hips of patients with osteoarthritis, there is a slight diminuation in total GAG $(11.7 \%)$ but a significant alteration of the concentrations of the component GAGs to 1 to 0.17 to 0.99 . This alteration is primarily due to an $11 \%$ decrease in the keratosulfate concentration and a $36.8 \%$ increase in the chondroitin 4-sulfate. (c) The only other abnormality noted was an increase in sulfation, as determined by the molar ratios, of the chondroitin 4-sulfate in the arthritic cartilage.

The findings in the normal tissues are essentially consistent with those for adult cartilage as reported by other investigators both for total quantity of GAG and percentage distribution $(33,34)$. Stockwell and Scott (4) have demonstrated by both histochemical and bio- 
TABLE IV

GAG Content of Normal and Arthritic Cartilage

\begin{tabular}{|c|c|c|c|c|c|c|}
\hline & \multirow{2}{*}{$\begin{array}{l}\text { Number } \\
\text { of } \\
\text { samples }\end{array}$} & \multirow[b]{2}{*}{$\begin{array}{l}\text { Avg. } \\
\text { Age }\end{array}$} & \multicolumn{4}{|c|}{ GAG content } \\
\hline & & & $\begin{array}{l}\text { Kerato- } \\
\text { sulfate }\end{array}$ & CH-4-SO4 & CH-6-SO، & Total GAG \\
\hline $\begin{array}{l}\text { Normal } \\
\text { SE }\end{array}$ & 13 & 77.5 & $\begin{array}{c}75.8 \pm 25.1 \\
7.0\end{array}$ & $\begin{array}{c}8.0 \pm 4.4 \\
1.2\end{array}$ & $\begin{array}{c}65.2 \pm 30.3 \\
8.4\end{array}$ & $\begin{array}{c}149.0 \pm 53.4 \\
14.3\end{array}$ \\
\hline $\begin{array}{l}\text { Arthritic } \\
\text { SE }\end{array}$ & 15 & 56.3 & $\begin{array}{c}58.8 \pm 19.9 \\
5.1\end{array}$ & $\begin{array}{c}10.8 \pm 5.8 \\
1.5\end{array}$ & $\begin{array}{c}62.0 \pm 26.8 \\
6.9\end{array}$ & $\begin{array}{c}131.5 \pm 49.8 \\
12.9\end{array}$ \\
\hline Average change in arthritic & & & $\begin{array}{l}-22.4 \% \\
{ }^{*} P<0.1\end{array}$ & $\begin{array}{c}+35 \% \\
P<0.2\end{array}$ & $-4.9 \%$ & $\begin{array}{l}-11.7 \% \\
P<0.30\end{array}$ \\
\hline
\end{tabular}

* As determined by the standard $t$ test.

Glycosaminoglycan content of the normal and arthritic cartilage based on CPC-cellulose column separation and identification There is an $11.7 \%$ decrease in the total GAG content, but the significance of this observation is questionable $(P<0.30)$. Of greater significance is the decrease in keratan sulfate $(22.4 \%)$ and the increase in chondroitin 4 -sulfate.

chemical studies that the keratan sulfate is not uniformly distributed in the cartilage but has its highest concentration in the basal layers, but the average values for the entire tissue conform with the values reported in this study. The variations as indicated by the standard deviations in Tables IV and V are also consistent with those reported in other series.

The change in the osteoarthritic cartilage differs somewhat from that reported by others. In 1953, Matthews (16) described a significant decrease in the chondroitin sulfate concentration of osteoarthritic knees, and several years later this was confirmed by Bollet and Nance (13) who also noted that the change was essentially proportional to the severity of the process.
Anderson, Ludoweig, Harper, and Engleman (33) failed to confirm these findings in a study of total mucopolysaccharides and sulfates in 60 samples of cartilage from around osteoarthritic human joints and suggested this finding confirmed the focal nature of the osteoarthritic lesion. Bollet attributed the major decrease in GAGs to a loss of chondroitin sulfate, which he felt resulted from the action of hyaluronidase-like enzyme or possibly a protease although he did note that the neutral sugars were also decreased $(12,13)$. Benmaman, Ludoweig, and Anderson found the keratan sulfate significantly reduced in arthritic cartilage (34).

The findings in this study confirm those of Anderson et al. (33) and Benmaman et al. (34) in that there was

TABLE V

Distribution of GAGs in Normal and Arthritic Cartilage

\begin{tabular}{|c|c|c|c|c|c|c|}
\hline & \multirow{2}{*}{$\begin{array}{c}\text { Number } \\
\text { of } \\
\text { samples }\end{array}$} & \multicolumn{5}{|c|}{ Percentage distribution of GAG } \\
\hline & & $\begin{array}{l}\text { Kerato- } \\
\text { sulfate }\end{array}$ & $\mathrm{CH}-4-\mathrm{SO}_{4}$ & $\mathrm{CH}-6-\mathrm{SO}_{4}$ & $\mathrm{KS} / \mathrm{CH}-\mathrm{S}$ & CH-4-S/CH-6-S \\
\hline $\begin{array}{l}\text { Normal } \\
\text { SE }\end{array}$ & 13 & $\begin{array}{c}51.7 \pm 4.5 \\
1.2\end{array}$ & $\begin{array}{c}5.7 \pm 2.5 \\
0.7\end{array}$ & $\begin{array}{c}42.5 \pm 6.1 \\
1.7\end{array}$ & $\begin{array}{c}1.09 \pm 0.20 \\
0.06\end{array}$ & $\begin{array}{c}0.143 \pm 0.072 \\
0.02\end{array}$ \\
\hline $\begin{array}{l}\text { Arthritic } \\
\text { SE }\end{array}$ & 15 & $\begin{array}{c}45.8 \pm 5.8 \\
1.5\end{array}$ & $\begin{array}{c}7.8 \pm 2.2 \\
0.6\end{array}$ & $\begin{array}{c}46.2 \pm 4.6 \\
1.2\end{array}$ & $\begin{array}{c}0.87 \pm 0.20 \\
0.05\end{array}$ & $\begin{array}{c}0.172 \pm 0.04 \\
0.01\end{array}$ \\
\hline Average change in arthritic & & $\begin{array}{c}-11.4 \% \\
{ }^{*} P<0.005\end{array}$ & $\begin{array}{r}+36.8 \% \\
P<0.05\end{array}$ & $\begin{array}{c}+8.7 \% \\
P<0.10\end{array}$ & $\begin{array}{l}-20.1 \% \\
P<0.01\end{array}$ & $\begin{array}{c}+20.3 \% \\
P<0.20\end{array}$ \\
\hline
\end{tabular}

* As determined by standard $t$-test.

Distribution of the glycosaminoglycans and ratios for normal and arthritic cartilage. Considerable difference is noted between the percentage of GAGs in normal and arthritic cartilage and, as is indicated here, there is an $11.4 \%$ decrease in keratan sulfate and a $36.8 \%$ increase in chondroitin 4-sulfate, both of higher significance. The change in chondroitin 6-sulfate is less marked and also less significant. As might be expected, the keratosulfate/chondroitin sulfate and chondroitin 4-/chondroitin 6-sulfate ratios reflect the percentage distribution. 


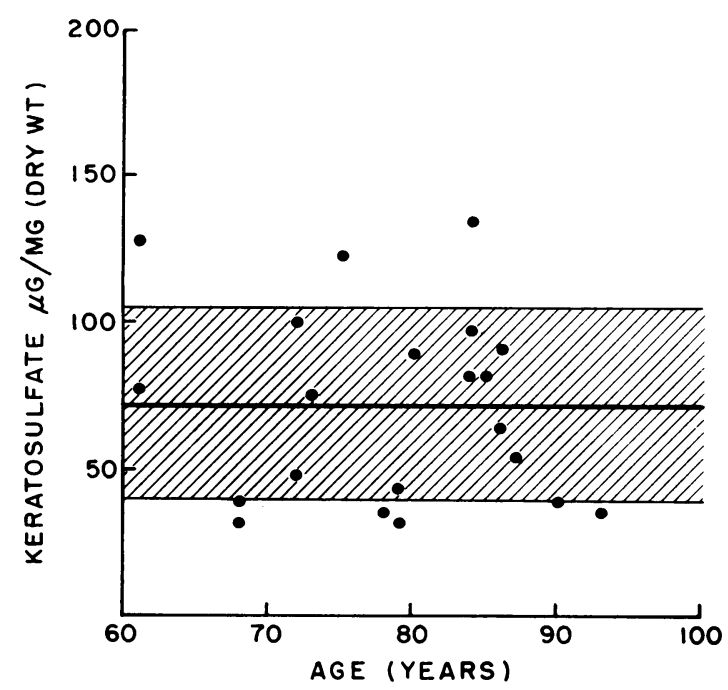

FIGURE 4 Graphic representation of keratan sulfate concentrations in cartilage of normal femoral heads from patients of various ages. An additional 8 femoral heads were studied and the data added to the 13 patients in the control series to provide a broader age distribution. No significant correlation can be detected. (Mean and standard deviations are shown.)

only an $11.7 \%$ decrease in total GAG, and this was principally in the keratan sulfate fraction. The lack of confirmation of the findings of Bollet et al. $(12,13)$ are probably based on the problems of sampling described in the early part of the discussion.

The increase in concentration of sulfate in one of the GAGs of the osteoarthritic tissue is a finding which has not been previously noted by those who have studied the chemical aspects of the disease $(12,33,34)$. The phenomenon of "oversulfation" is well -recognized, particularly in the keratan sulfates $(31,32)$. The data presented here offer no explanation for the observed increase, but clearly further study is indicated to confirm the finding and possibly to ascertain the sterochemical site of the "extra" sulfates.

In critical evaluation of the data, the major abberations in osteoarthritic cartilage are the increase in chondroitin 4-sulfate and decrease in keratan sulfate. These changes may be due to an alteration in the synthetic pattern of the chondrocyte or a selective degradation favoring keratosulfate and sparing chondroitin sulfate. The latter alternative, selective degradation, seems somewhat unlikely since chondroitin 4- and 6-sulfates are probably equally susceptible to autolytic local enzymes, and keratan sulfate is probably the most stable of the GAGs, with a half-life of over 140 days as reported by Davidson and Small in material from nucleus pulposus (37). Keratan sulfate is also thought to be resistant to hyaluronidase $(2,3)$, thus eliminating the only other likely mechanism of depolymerization or degradation in the diseased joint.

The alternative possibility, that of an altered product of synthesis, is much more intriguing. A number of studies have demonstrated that the rate of synthesis of polysaccharides is markedly increased in osteoarthritis $(12,17,18)$, and several investigations have suggested that this anabolic increase is proportional to the severity of the disease, possibly on the basis of a negative "feedback" system $(14,15,17,19)$.

It has been shown both histologically and with thymidine studies that the cells of articular cartilage from osteoarthritic joints are actively replicating, a privilege they do not ordinarily enjoy after maturity (17). Ultramicroscopic studies of the osteoarthritic cells suggest an extremely active cell with well-developed organelles in contradistinction to the more effete cell of the normal mature tissue. ${ }^{2}$

It is possible to speculate on the basis of these observations that the chondrocyte, under the influence of the chronic osteoarthritic stress, undergoes a modulation to a chondroblastic phase and assumes the structural appearance, replicative powers, and synthetic processes of the cells from a younger individual. The matrix synthesized by such a cell should, in theory, be lower in keratosulfate, and if young enough, richer in chondroitin 4-sulfate-essentially the findings noted in this study.

The formulation described above is obviously speculative and although based on reasonable bits of evidence, lacks clear definition and positive proof. It is still a very tempting one and would suggest the possibility that damaged cartilage may attempt repair by the only method available: conversion of its cell from a balance maintenance organ (the chondrocyte) to one engaging in net synthesis (the chondroblast).

\section{ACKNOWLEDGMENTS}

This work was supported in part by Research Grant AM11382-04 from the National Institute of Arthritis and Metabolic Diseases.

\section{REFERENCES}

1. Jeanloz, R. 1960. The nomenclature of mucopolysaccharides. Arthritis Rheum. 3: 233.

2. Muir, H. 1964. Chemistry and metabolism of connective tissue glycosaminoglycans (mucopolysaccharides). Int. Rev. Connective Tissue Res. 2: 101.

3. Schubert, M., and D. Hamerman. 1968. A Primer on Connective Tissue Biochemistry. Lea \& Febiger, Philadelphia.

4. Stockwell, R. A., and J. E. Scott. 1967. Distribution of acid glycosaminoglycans in human articular cartilage. Nature (London). 215: 1376.

\footnotetext{
${ }^{2}$ Weiss, C., and S. Mirow. An ultrastructural study of osteoarthritic human articular cartilage. Manuscript in preparation.
} 
5. Kaplan, D., and K. Meyer. 1959. Ageing of human cartilage. Nature (London). 183: 1267.

6. Stockwell, R. A., and J. E. Scott. 1965. Observations on the acid glycosaminoglycan (mucopolysaccharide) content of the matrix of ageing cartilage. Ann. Rheum. Dis. 24: 341 .

7. Shetlar, M. R., and Y. F. Masters. 1955. Effect of age on polysaccharide composition of cartilage. Proc. Soc. Exp. Biol. Med. 90: 31 .

8. Mathews, M. B., and S. Glagov. 1966. Acid mucopolysaccharide patterns in aging human cartilage. J. Clin. Invest. 45: 1103.

9. Kuhn, R., and H. J. Leppelmann. 1958. Galaktosamin und glucosamin im Knorpel in Abhängigkert vom Lebensalter. Justus Liebigs Ann. Chem. 611: 254.

10. Stedworthy, G., Y. F. Masters, and M. R. Shetlar. 1958. The effect of aging on mucopolysaccharide composition of human costal cartilage as measured by hexosamine and uronic acid composition. J. Gerontol. 13: 10.

11. Loewi, G. 1963. Changes in the ground substance of ageing cartilage. J. Pathol. Bacteriol. 65: 381.

12. Bollet, A. J., J. R. Handy, and B. C. Sturgell. 1963. Chondroitin sulfate concentration and protein polysaccharide composition of articular cartilage in osteoarthritis. J. Clin. Invest. 42: 853.

13. Bollet, A. J., and J. L. Nance. 1966. Biochemical findings in normal and osteoarthritic articular cartilage. II. Chondroitin sulfate concentration and chain length, water and ash content. J. Clin. Invest. 45: 1170.

14. Bollet, A. J. 1967. Connective tissue polysaccharide metabolism and the pathogenesis of osteoarthritis. Advan. Intern. Med. 13: 33.

15. Bollet, A. J. 1969. An essay on the biology of osteoarthritis. Arthritis Rheum. 12: 152.

16. Matthews, B. F. 1953. Composition of articular cartilage in osteoarthritis. Brit. Med. J. 2: 660 .

17. Mankin, H. J., and L. Lippiello. 1970. Biochemical and metabolic abnormalities in articular cartilage from osteoarthritic human hips. J. Bone Joint Surg. Amer. Vol. 52 A : 424.

18. Collins, O. H., and T. F. McElligott. 1960. Sulfate $\left({ }^{35} \mathrm{SO}_{4}\right)$ uptake by chondrocytes in relation to histological changes in osteoarthritic human articular cartilage. Ann. Rheum. Dis. 19: 318.

19. Chrisman, O. D. 1969. Biochemical aspects of degenerative joint diseases. Clin. Orthop. 64: 77.

20. Rondle, C. J. M., and W. T. J. Morgan. 1955. The determination of glucosamine and galactosamine. Biochem. J. $61: 586$.

21. Bitter, T., and H. Muir. 1962. A modified uronic acid and carbazole reaction. Anal. Biochem. 4: 330.

22. Khym, J. X., and D. G. Doherty. 1952. Analysis and separation of glucuronic and galacturonic acids by ion exchange. J. Amer. Chem. Soc. 74: 3199.

23. Antonopoulos, C. A. 1962. A modification for the determination of sulfate in mucopolysaccharides by the benzidine method. Act. Chem. Sc. 16: 1521.

24. Dische, Z. 1962. Color reactions of hexoses. Methods Carbohyd. Chem. 1: 490.

25. Reissig, J. L., J. L. Strominger, and L. F. Leloir. 1955. A modified colorimetric method for the estimation of N-acetyl amino sugars. J. Biol. Chem. 217: 959.

26. Lowry, O. H., N. J. Rosebrough, A. L. Farr, and R. J. Randall. 1951. Protein measurement with the Folin phenol reagent. J. Biol. Chem. 193: 265.

27. Lippiello, L., and H. Mankin. 1971. A thin layer chromatographic method for separation and identification of the acidic glycosaminoglycans. Anal. Biochem. 39: 54.

28. Svejcar, J., and W. von B. Robertson. 1967. Microseparation and determination of mammalian acidic glycosaminoglycans (mucopolysaccharides). Anal. Biochem. $18: 333$.

29. Hjertquist, S. O., and L. Vejlens. 1968. The glycosaminoglycans of dry compact bone and epiphyseal cartilage in the normal state in experimental hyperparathyroidism. Calcified Tissue Res. 2: 314.

30. Mathews, M. B., and M. Inouye. 1961. The determination of chondroitin sulfate C-type polysaccharides in mixtures with other acid mucopolysaccharides. Biochim. Biophys. Acta. 53: 509 .

31. Mathews, M. B., and J. A. Cifonelli. 1965. Comparative biochemistry of keratosulfates. J. Biol. Chem. 240: 4140.

32. Seno, N., K. Meyer, B. Anderson, and P. Hoffman. 1965. Variations in keratosulfates. J. Biol. Chem. 240: 4005.

33. Anderson, C. E., J. Ludowieg, H. A. Harper, and E. P. Engleman. 1964. The composition of the organic component of human articular cartilage. J. Bone Joint Surg. Amer. Vol. 46 A : 1176.

34. Benmaman, J. D., J. Ludowieg, and C. E. Anderson. 1969. Glucosamine and galactosamine distribution in human articular cartilage: relationship to age and degenerative joint disease. Clin. Biochem. 2: 461.

35. Antonopoulos, C. A., S. Gardell, J. A. Szirmai, and E. R. De Tyssonsk. 1964. Determination of glycosaminoglycans (mucopolysaccharides) from tissue on the microgram scale. Biochim. Biophys. Acta. 83: 1.

36. Gardell, S., and J. A. Szirmai. 1967. Microchemical analysis of glycosaminoglycans (mucopolysaccharides) in connective tissues. Connective Tissue. 1: 330.

37. Davidson, E. A., and W. Small. 1963. Metabolism in vivo of connective tissue mucopolysaccharides. III. Chondroitin sulfate and keratosulfate of cartilage. Biochim. Biophys. Acta. 69: 459. 